\title{
Yarrenyty Arltere Artists
}

\begin{tabular}{c}
\hline MARLENE RubuntJa \\
Dulcie SHARPE \\
SOPHIE WALLACE \\
LEONIE SHEEdY
\end{tabular}

-EDITORS' INTRODUCTION

Yarrenty Arltere Art Centre is located in Larrapinta Valley, one of the oldest urban Aboriginal settlements on Arrernte country and one of the first of the eighteen housing associations or 'town camps' to be formally recognised within the history of Mbuntua/Alice Springs. The art centre is part of the Yarrenyty Arltere Learning Centre, established in 2000, which is itself part of Tangentyere Council, the greater representative body incorporated in 1979. The Tangentyere Council lobbies on behalf of Alice Springs town camp residents across the spectrum of land rights, housing, employment and other legal and health services as part of the greater social services it delivers. Thus, it is not arbitrary that in the piece below Yarrenyty Arltere artists speak of their art work less in terms of Dreaming than in explicit terms about ISSN 1837-8692

\footnotetext{
Cultural Studies Review 2015. @ 2015 Marlene Rubuntja, Dulcie Sharpe, Sophie Wallace and Leonie Sheedy. This is an Open Access article distributed under the terms of the Creative Commons Attribution 4.0 Unported (CC BY 4.0) License

(https://creativecommons.org/licenses/by/4.0/), allowing third parties to copy and redistribute the material in any medium or format and to remix, transform, and build upon the material for any purpose, even commercially, provided the original work is properly cited and states its license.
} 
what the art and learning centre at Larrapinta Valley has created: an Aboriginally owned, managed and directed space of health, healing and community-capacity building. Indeed, this is what is portrayed in the artists' first soft sculpture animation, the self-referential Antanette and Tom (2010).

Yarrenyty Arltere art centre was established more than three decades after the first remote Western Desert community art centre of Papunya Tula Artists in 1972. The rationale for the establishment of an art centre at Larrapinta Valley drew directly upon what had, by then, become the evidence of the benefits of remote community art centres. These were not solely the provision of an income base for Aboriginal people but the far more important, if difficult to quantify, qualities that Tim Acker, Lisa Stefanoff and Alice Woodhead call the 'critical question of cultural survival, identity, livelihood and individual and community wellbeing' ${ }^{1}$ associated with remote Aboriginal art centres and aesthetic practice today. The Yarrenyty Arltere motto, 'own this place', speaks to how important the self-determining propriety of art centres is, explicitly in the marginalised context of Alice Springs town camps, whose purported 'dysfunction' informed the 2007 Northern Territory Emergency Response intervention.

Community art centres are often described as the 'interface' between Indigenous culture and the art market; the first point of inclusion of artists within the global economy. The Yarreynty artists explicitly identify their art program as 'an enterprise' in these terms. But as they also figure it, art centres provide far more than simply a local, collective, studio-to-market space for art production. As Jennifer Biddle describes, art centres provide one of the few sources of non-government income for Aboriginal people, and therefore actively defy the perception of remote people as without income opportunities, or the so-called 'lack of engagement' of Aboriginal people in employment and professional development on remote homelands. ${ }^{2}$ Thus, the centres build self-esteem and confidence directly, as the artists narrate. Art centres provide one of the few institutional places in which the workplace is driven by, concerned with and governed by traditional law and culture, that are open and accessible to all members of the community, and which have a role directly linked to the healthy-making sustainability of contemporary community life. As Hetti Perkins attested in the 2014 Desert Mob Symposium key 
note address: 'Art centres build community pools, set up aged care and dialysis services, work with schools, help with sorry business, the list goes on and on.'3

In less than a decade, Yarrenyty Arltere art works have become represented in almost all major national Australian galleries. Their works have been shortlisted for the Togart Contemporary Art Award and the Western Australian Indigenous Art Award. In 2013, Rhonda Sharpe won the 3D New Media Art Award at the 30th Telstra National Aboriginal and Torres Strait Islander Art Awards for her work They Came from Nowhere.

The history told by the Yarrenyty Arltere artists below is one of the strongest statements for the importance of community art centres and one of the first to be published formally in the artists' own voice and terms. It was co-written by Leonie Sheedy (former coordinator of Larrapinta Valley Learning Centre), Sophie Wallace (current art centre coordinator for Yarrenyty Arltere) and artists Marlene Rubuntja and Dulcie Sharpe. We are reproducing it in a format close to its original spoken presentation to exemplify what the artists identify as their own story-telling 'from the heart of a people finding a way to tell their story that does not give away everything at once'. Their talk concludes with two recent collaborative art works, a sculpture and screenprint by Marlene Rubuntja and Sally Rubuntja, accompanied by an artists' statement.

My name is Sophie Wallace and I am the art coordinator of Yarrenyty Arltere Artists, situated at the Yarrenyty Arltere Learning Centre in Larapinta Valley Town Camp, Alice Springs. The town camp was established in 1975 by artist and Aboriginal elder (and father to Marlene) Wenten Rubuntja. It originally comprised three families, the Rubuntjas, the Ebatarinjas and the Namatjiras.

I'd like to open my talk with a quote from the artist Marlene Rubuntja:

They were painters but we are sewers. But we both work with our hands.

This is important. We love sewing the same as other people love their painting. When we sew it makes us feel really good. We don't think of anything except what we are making.

In my talk this afternoon I will give you a brief background to the art program and the learning centre and try to show how the art program has been a healing and 
dynamic area of strength, ability and engagement and how this has built self esteem that is transferred into other parts of people's lives.

I will give you an overview of the innovative art that is produced by the artists, showing how the art program is key to expression, communication and connection and how people's voice's are expressed in many ways, often more in what they do and less in what they say.

The art centre honours people's strengths and provides safety. It also challenges people into new paths of learning-to extend themselves, their talents, skills and creative work. The art centre, 'makes us strong for our thinking and our bodies'.

The art centre is a 'refuge' where people learn together and build on positive experiences. It is where people are able to connect and talk through issues of art or issues of home. Having conversations while you are doing things is often easier.

The story of the art program is very much a story about people. It is a story of strength, resilience, talent, healing.

Before the opening of the learning centre, Larapinta Valley town camp was known as a community crippled by substance abuse and violence. It was seen as a community where children and young people had no engagement with education, where children and young people were involved in repetitive poverty based crime and where children as young as five were engaging in daily inhalant use of petrol, spray paint or glue. It was known as the main place of 'sniffing' in Alice Springs and as such attracted large numbers of visitors gathering at the community to use inhalants. It was a community with poor, spasmodic and uncoordinated access to mainstream services; a community with long-term unemployment.

Yarrenyty Arltere Learning Centre developed in response to people's needsthe needs of the young people who were serious 'sniffers' and of the community who were desperate to see changes in their lives and the lives of their kids.

Now, the community can be proud. They have dramatically reduced levels of substance misuse, there has been a significant reduction in visitors gathering at the community using inhalants and community strategies are in place to deal with inhalant use. There is a new generation of children regularly attending school; a generation who have never been involved in substance use. The community now has coordinated access to mainstream services including child protection, improved 
health and improved access to health services and increased internal strength including leadership from within the community

—'OWN THIS PLACE'

So simple and yet so significant: 'own this place'.

The degree to which people are often marginalised in Alice Spring cannot be overstated. It is extremely important to have a localised program where people are comfortable to engage and to allow people to remove themselves from stress and slowly address the many areas of disadvantage that they face. The art room is such a place.

It is in the art room that people can sit quietly, peacefully-talk to each other, share ideas and express themselves through art. People are able to learn new skills, have a focus and explore their art practice. This is their place-without judgement, without scrutiny - a place of safety where there is respect and a sense of belonging.

Central to the art program's success has been strong local governance. People want an enterprise, they want to work and have a job they can go to daily; art provides this opportunity. Art has become a main strategy to deal with the dire circumstances of poverty and violence.

'Think about what to make instead of thinking bad things.' This is a common statement used when people talk about why they like doing art. Its role in relieving stress and grief is significant.

There is often little space in people's home lives: living areas are often overcrowded, alcohol affects families in different ways, people are often sleep deprived; high levels of stress makes positive life activities difficult to pursue at home. People are often living with grief, trauma, sadness and economic stress; depression is a risk for many; poverty is still pervasive and Sorry Business still occurs too often.

The art centre is a place that daily represents the success and ability of the community. It is a place the community have created through their inspiration, talent and work.

The artists work in three main areas: soft sculpture, textiles and printmaking. Their work is strongly underpinned by its own culture, that of people living in town 
camps for a number of generations. It speaks of country, local flora and fauna, family, cattle station and town camp life.

The sculptures, made from recycled woollen blankets, sourced from second hand shops across Australia, are dyed using local plants, tea and rusty bits of metal. Beautiful patterns and colours are created through this dying process and they are then used as the base material to create the soft sculptures. People draw, cut, pin, stitch and sew, and all the while talk, laugh, be silent, eat, drink, sleep and create work that is humorous and beautiful, rough and sculptural, ridiculous, dramatic and inspiring.

People are developing a unique identity through this art, one that represents the achievements of strong and resilient town camp people. The sculptures and the prints, are contemporary, they are from the heart of people who are finding a way to tell their story that does not give away everything at once. So many stories come into this art room, so many stories that make you laugh and cry, that make you exhausted and relieved, that make you grateful, that make you want to run home to your comfortable life but that keep you coming back each day. And through this art, which is new and innovative, people can find a voice that tells the wider community that they are worth listening to, that they are important, that they are healing themselves and their families.

This art, the sculptures, the prints and the textiles are exciting expressions of life and culture that are made by severely disadvantaged town campers, yet sell and connect with people across Australia. The art is powerful because it is innovative and inventive just like the artists. It embraces 'both ways' and then redefines it all over again so that it has a new voice, a voice from resilient town camp people who are able to respond and adapt to extraordinary challenges, daily.

And this ability to respond has also led the artists in conjunction with the Yarrenyty Arltere Learning Centre (YALC) multimedia room make to soft sculpture animations. Animation has become a new and exciting media for the artists to tell their stories.

The art enterprise has given opportunity for increased pride and self esteem, increased confidence and well being, healing from grief and trauma, strong role modelling, community leadership and family strengthening, improved governance, decision making and engagement, improved financial and living skills, improved 
economic access and employment, improved social inclusion. Ten years ago the community set up the learning centre to address their problems in a holistic way that respected family and culture. The art centre has emerged as a core part of this strategy.

It is a place for adults and young people to come-to share time, show their talents and become mentors and role models. Rather than be seen as drinkers, victims of violence, petrol sniffers, they are seen as artists, creators, innovators, leaders, organisers, planners, as well as parents and carers. People are recognised for their wisdom and skills and abilities.

People are building an enterprise that is based on healing.

The art centre is a celebration of life, culture, hope and aspiration for the next generations.

At the art centre people can focus on something positive, creative and challenging. They are able to create some balance-some reality that is positive, able, affirming and satisfying. Something they can control and enjoy. This is healing and empowering.

—Marlene RubuntJa And Sally RubuntJa, 3 April 2013

We are proud ladies; you can see how we stand with our arms stretched out, not afraid to tell people that this place, Yarrenyty Arltere, is our place. We are the women of this place, making art, making laughing, making strong. That body is painted with stories and markings, just like real woman, all covered in markings. But look, her arms are open like when people talk at meetings; her arms are open because she is talking for everyone to hear.

And see those three trees on her body, Sally and I, two sisters, sit under those trees in the shade, sometimes doing sewing, sometimes just sitting.

There is also a river on one side arm, that arm up high so that river can flow down and feed those trees and wash that lady clean. The water stays under those trees and keeps them alive so we can sit under the shade of those trees. So woman can sit under the shade and do more sewing if they want, of they can just sit there and rest and tell stories about the old times and the new times. 


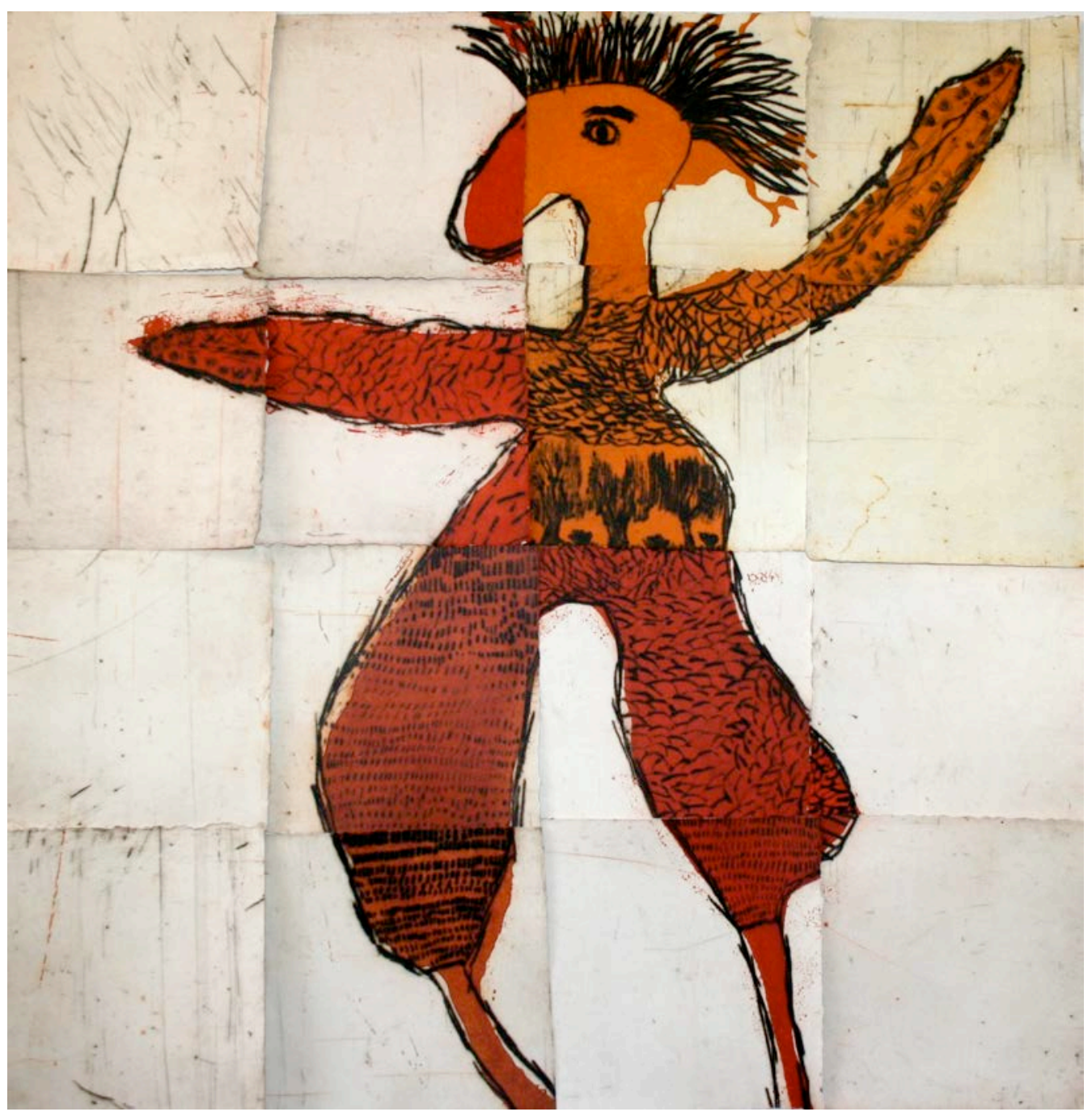

Image 1: Sally Rubuntja and Marlene Rubuntja, See How We Stand, Proud with Our Arms Open! 2013, etching, $60 \mathrm{~cm}$ x $60 \mathrm{~cm}$ (photo: S. Wallace; (C) Yarrenyty Arltere Artists 2013) 


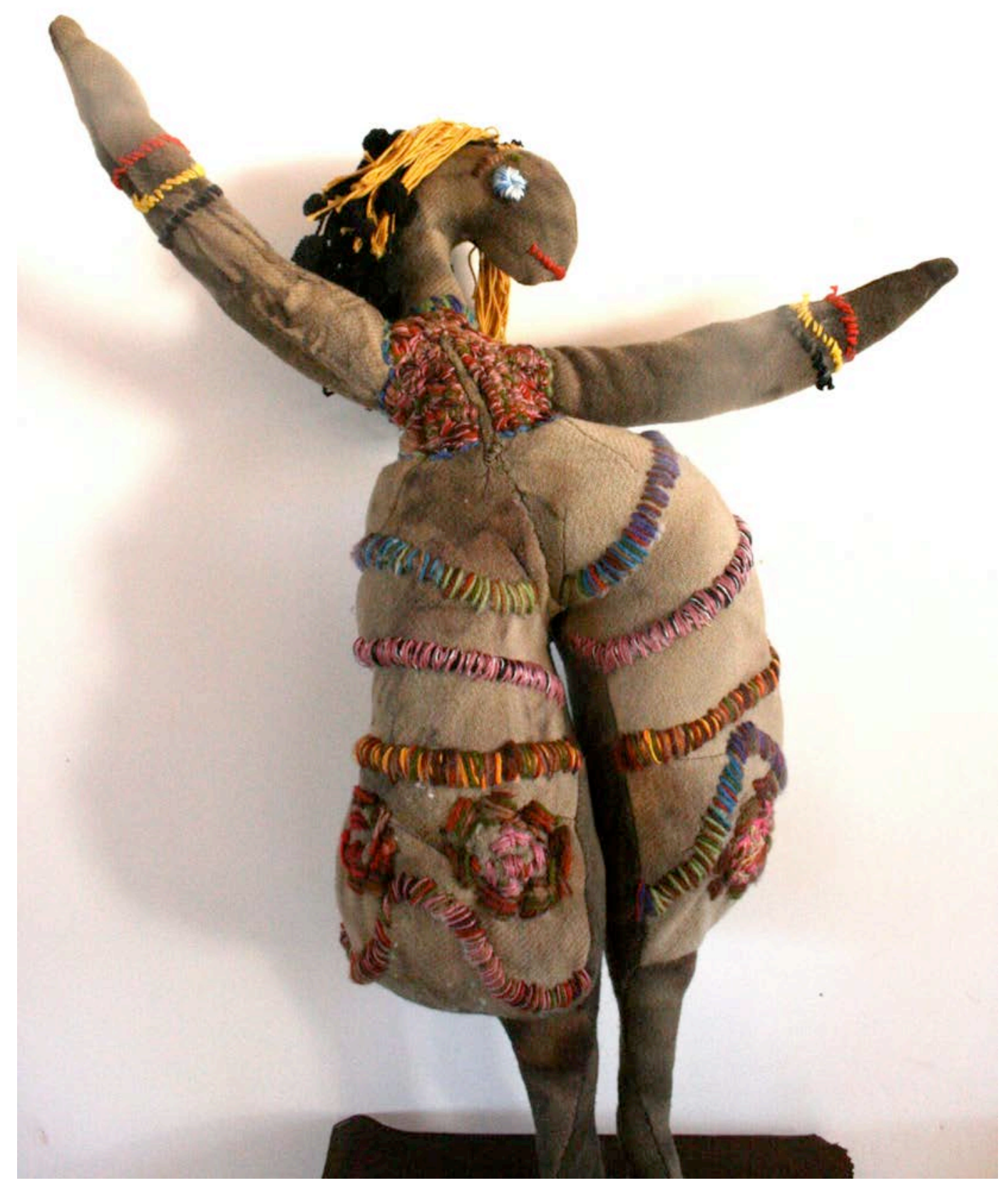

Image 2: Sally Rubuntja and Marlene Rubuntja, Woman with Arms Up Because She is Proud! 2013, $67 \mathrm{~cm}$ x $60 \mathrm{~cm}$ x $18 \mathrm{~cm}$ (photo: S. Wallace (C) Yarrenyty Arltere Artists 2013) 
Marlene Rubuntja was born in Alice Springs. Her mother's country is Ntaria (Hermansburg). Marlene is an Arrernte woman who proudly calls Larapinta Valley Town Camp her home. She is an artist, a film maker, a writer and a spokeswoman for the Yarrenyty Arltere Artists. Marlene's work has been acquired for major public and private collections. She has exhibited her work in Australia and overseas.

Dulcie Sharpe was born at Jay Creek, out bush; she is a Luritja woman whose mother is from Papunya. Dulcie works every day as an artist at the Yarrenyty Arltere Art Centre. She is a respected elder of the community and a positive role model for other artists. Dulcie's work has been exhibited in Australia and overseas. Her work is held in major public and private collections. In 2013 Dulcie was highly commended in the WA Indigenous art award and in 2014 she was a finalist in the Telstra NATISIAA art award Darwin.

Sophie Wallace has worked as art coordinator for the Yarrenyty Arltere Artists since it became an enterprise in 2009. Prior to this she ran a small not-for-profit tour company called 'beanies baskets and bushtucker'. Sophie is also a teacher and worked for many years on remote Western Desert communities and in Arnhem Land as a classroom teacher and an ESL specialist.

Leonie Sheedy has worked in community development in the Northern Territory for eighteen years. She was the coordinator for the Yarrenyty Arltere Learning Centre, in Alice Springs, from 2000 to 2012. Prior to this she was a teacher with Yuendumu Community Education Centre for two years. She is currently working as the Director of Policy and Practice for Children's Ground.

\footnotetext{
1 Tim Acker, Lisa Stefanoff and Alice Woodhead, Aboriginal and Torres Strait Islander Art Economies Project: Literature Review, CRC-REP Working Paper CW010, Ninti One Limited, Alice Springs, 2013. 2 Jennifer Biddle, 'Introduction', Remote Avant-Garde: Aboriginal Art Under Occupation, Duke University Press, Durham and London, forthcoming, 2015.

3 Hetti Perkins, 'Reflections and Projections', key note speech at Desert Mob Symposium 2014 <http://desart.com.au/desert-mob-symposium/>.
} 


\section{-BiBLIOGRAPHY}

Acker, T., L. Stefanoff and A. Woodhead, Aboriginal and Torres Strait Islander Art Economies Project: Literature Review, CRC-REP Working Paper CW010, Ninti One Limited, Alice Springs, 2013.

Biddle, J., 'Remote Avant-Garde: Aboriginal Art Under Occupation, Duke University Press, Durham and London, forthcoming, 2015.

Perkins, H., 'Reflections and Projections', key note speech at Desert Mob Symposium 2014 <http://desart.com.au/desert-mob-symposium/>. 